\title{
Sustained Release d-Amphetamine Reduces Cocaine but not 'Speedball'-Seeking in Buprenorphine-Maintained Volunteers: A Test of Dual-Agonist Pharmacotherapy for Cocaine/Heroin Polydrug Abusers
}

\author{
Mark K Greenwald*,', Leslie H Lundahl' and Caren L Steinmiller ${ }^{1,2}$ \\ 'Substance Abuse Research Division, Department of Psychiatry and Behavioral Neurosciences, Wayne State University School of Medicine, \\ Detroit, MI, USA; ${ }^{2}$ Department of Pharmacology and Toxicology, University of Toledo, Toledo, OH, USA
}

\begin{abstract}
The aim of this study was to determine whether oral sustained release $d$-amphetamine (SR-AMP) reduces cocaine and opioid/cocaine combination ('speedball'-like) seeking in volunteers with current opioid dependence and cocaine dependence. Following outpatient buprenorphine (BUP) $8 \mathrm{mg} /$ day stabilization without SR-AMP, eight participants completed a 3-week in-patient study with continued BUP $8 \mathrm{mg} /$ day maintenance and double-blind ascending SR-AMP weekly doses of 0, 30, and $60 \mathrm{mg} /$ day, respectively. After 3 days (Saturday-Monday) stabilization at each SR-AMP weekly dose (0, 15, or $30 \mathrm{mg}$ administered at 0700 and 1225 each day), on TuesdayFriday mornings (0900-1200 hours), participants sampled four drug combinations in randomized, counterbalanced order under doubleblind, double-dummy (intranasal cocaine and intramuscular hydromorphone) conditions: cocaine (COC I00 mg + saline); hydromorphone (COC 4 mg + HYD 24 mg); 'speedball' (COC 100 mg + HYD 24 mg); and placebo (COC 4 mg + saline). Subjective and physiological effects of these drug combinations were measured. From 1230 to 1530 hours, participants could respond on a choice, 12-trial progressive ratio schedule to earn drug units ( I/ /2th of total morning dose) or money units (US\$2). SR-AMP significantly reduced COC, but not HYD or speedball, choices and breakpoints. SR-AMP also significantly reduced COC subjective (eg, abuse-related) effects and did not potentiate COC-induced cardiovascular responses. This study shows the ability of SR-AMP to attenuate COC self-administration, as well as its selectivity, in cocaine/heroin polydrug abusers. Further research is warranted to ascertain whether SR-AMP combined with BUP could be a useful dual-agonist pharmacotherapy.

Neuropsychopharmacology (2010) 35, 2624-2637; doi:10.1038/npp.2010.175; published online 29 September 2010
\end{abstract}

Keywords: d-Amphetamine; cocaine; drug self-administration; buprenorphine; polydrug abuse

\section{INTRODUCTION}

Cocaine and heroin dependence each pose serious and substantial public health, social, and economic problems (ONDCP, 2003). Unfortunately, many opioid-dependent individuals who are treated with agonist medications such as methadone (MTD) and buprenorphine (BUP) still abuse cocaine, either independently or in heroin/cocaine 'speedball' combination (Magura et al, 1991; Torrens et al, 1991; Schütz et al, 1994; Craddock et al, 1997; Beswick et al, 2001; Leri et al, 2004). Cocaine and opioid use disorders often co-occur and this conjunction, relative to opioid depen-

*Correspondence: Dr MK Greenwald, Substance Abuse Research Division, Department of Psychiatry and Behavioral Neurosciences, 2761 East Jefferson Ave., Detroit, Ml 48207, USA, Tel: + I 313993 3965, Fax: + I 313993 1372, E-mail: mgreen@med.wayne.edu Received 18 May 2010; revised 27 August 2010; accepted 28 August 2010 dence only, is associated with worse treatment outcomes (Perez et al, 1997; Preston et al, 1998; DeMaria et al, 2000; Downey et al, 2000; Sofuoglu et al, 2003; Tzilos et al, 2009), antisocial personality disorder (King et al, 2001), and risky drug-injection and sexual behaviors (Grella et al, 1995; Hudgins et al, 1995). Cocaine/heroin abusers engage in a disproportionate share of income-generating crimes (Strug et al, 1985; Cross et al, 2001). These adverse sequelae provide a compelling reason to find effective treatments for heroin-dependent individuals who abuse cocaine.

Substitution pharmacotherapies are an attractive option because they can produce cross-tolerance to drug reinforcement, replace harmful drug use behaviors with safer doses and routes of administration, and suppress withdrawal symptoms, thereby facilitating extinction and prolonged abstinence (Gorelick et al, 2004; Shearer and Gowing, 2004). Although agonist replacement is safe and effective for treating dependence on opioids (Kreek, 2000), MTD and 
BUP - despite some supportive data (Schottenfeld et al, 1993; Montoya et al, 2004) - are usually considered to be ineffective for reducing cocaine abuse. Most human laboratory tests of agonist-like agents for reducing cocaine self-administration have yielded negative results (Haney and Spealman, 2008). However, promising candidate medications under investigation include sustained-release formulations of monoamine agonists, which act on dopamine (DA) and norepinephrine (NE) neurotransmission (Rothman et al, 2002; Grabowski et al, 2004b; Castells et al, 2007), mechanisms that underlie the reinforcing effects of cocaine.

In previous studies, the effects of acute $d$-amphetamine (AMP) administration on cocaine self-administration have been mixed (Mansbach and Balster, 1993; Glowa et al, 1995; Lynch et al, 1998; Foltin and Evans, 1999; Barrett et al, 2004). In contrast, repeated or continuous AMP administration consistently produces significant reductions in cocaine-reinforced responding in rats (Peltier et al, 1996; Chiodo et al, 2008; Chiodo and Roberts, 2009), and cocaine $v s$ food choice in rhesus monkeys (Negus, 2003; Negus and Mello, 2003a, b). Importantly, chronic relative to acute AMP produces greater effects on $D_{1}$ and $D_{2}$ receptor responses (Ginovart et al, 1999; Kim et al, 2001) and glutamatergically mediated synaptic plasticity ( $\mathrm{Li}$ and Kauer, 2004), although the impact of these neuroadaptations on responses to cocaine is not well understood. In human subjects, maintenance on sustained release AMP (SR-AMP) significantly reduced subjective effects, while increasing some physiological effects of intranasal cocaine (cumulative doses of 4,34, and $94 \mathrm{mg}$ cocaine after 3-5 days of stabilization on 0,15 , and $30 \mathrm{mg} /$ day SR-AMP; Rush et al, 2009). At doses up to $60 \mathrm{mg} / \mathrm{day}, \mathrm{SR}$-AMP reduced cocaine use in two outpatient, placebo-controlled, randomized clinical trials, including one study with MTD-maintained, cocaine/heroin-dependent patients (Grabowski et al, 2001, 2004a).

Evidence from animal laboratory studies indicates that $\mu$-opioid/cocaine combinations are self-administered in a dose-related manner (Mello et al, 1995; Rowlett and Woolverton, 1997; Duvauchelle et al, 1998; Rowlett et al, 1998, 2005; Cornish et al, 2005; Negus, 2005; Winger et al, 2006; Woolverton et al, 2008) and that speedball-maintained responding can be reduced by pretreatment with higher-dose BUP (Mello and Negus, 1998) or combined BUP/SR-AMP (Mello and Negus, 2007). Human laboratory studies with heroin-dependent participants have not examined actual seeking of cocaine or speedball combinations, nor interventions to reduce this drug use; this is a key feature of medication development efforts (Comer et al, 2008).

The present human laboratory study evaluated the potential efficacy and safety of a dual-agonist pharmacotherapy approach for non-treatment-seeking individuals with concurrent opioid and cocaine use disorders, using BUP and SR-AMP. The partial $\mu$-opioid agonist BUP is an alternative to MTD that could be paired with SR-AMP (providing clinical flexibility), and BUP may be safer for and preferred by some patients. Our primary hypothesis was that, during BUP maintenance, SR-AMP would dosedependently attenuate cocaine-seeking behavior and might reduce 'speedball'-like (cocaine + hydromorphone), but not hydromorphone-seeking behavior. Our secondary hypotheses were that SR-AMP would suppress cocaine withdrawal symptoms and reduce cocaine's subjective and physiological effects. Finally, the safety of this medication (and experimental drug) combination also was evaluated.

\section{MATERIALS AND METHODS}

\section{Participants}

The local Institutional Review Board approved this study, which was conducted according to the Declaration of Helsinki. Volunteers, aged 18-55 years, were recruited by advertisements and word-of-mouth and not seeking drug abuse treatment. All provided informed consent. Screening included medical history, blood and urine chemistry, electrocardiogram and tuberculin testing, physical exam, and psychiatric interview (SCID-IV; First et al, 1996).

Volunteers met the DSM-IV criteria for current opioid dependence and cocaine abuse or dependence. Volunteers had to provide a supervised urine sample positive for opioids and cocaine and negative for MTD, amphetamines, and barbiturates. Benzodiazepine- or THC-positive urine samples were allowed, but sedative and cannabis use disorder diagnoses were exclusionary. Volunteers had to provide alcohol-free breath samples $(<0.002 \%)$.

Volunteers were excluded if they: met the DSM-IV criteria for current axis I disorders, except opioid and nicotine dependence and cocaine abuse/dependence; were taking prescribed medications; had chronic health problems; were cognitively impaired (IQ < 80) based on Shipley Institute of Living Scale (Zachary, 1991); or scored $>15$ on Medical Fear Survey Injection and Blood Withdrawal Phobia subscale (Kleinknecht et al, 1999).

\section{Study Design}

Participants completed this 3-week in-patient study (Figure 1) during BUP $8 \mathrm{mg} /$ day maintenance. SR-AMP maintenance doses $(0,30$, and $60 \mathrm{mg} /$ day $)$ were administered in ascending order under double-blind conditions. After 3 days (Saturday-Monday) stabilization at each SR-AMP dose, on Tuesday-Friday mornings, participants sampled four drug combinations in randomized, counterbalanced order under double-blind, double-dummy (intranasal cocaine and intramuscular hydromorphone) conditions: cocaine (COC $100 \mathrm{mg}+$ saline); hydromorphone (COC $4 \mathrm{mg}+$ HYD $24 \mathrm{mg}$ ); 'speedball' (COC $100 \mathrm{mg}+\mathrm{HYD}$ $24 \mathrm{mg}$ ); and placebo (COC $4 \mathrm{mg}+$ saline). During afternoons, participants responded on a choice, 12-trial progressive ratio (PR) schedule to earn units of drug (1/12th of sampling dose) or money (US\$2).

The experimental design for sampling sessions was: SR-AMP dose $(0,30$, and $60 \mathrm{mg} /$ day $) \times$ COC total dose $(4$ and $100 \mathrm{mg}) \times$ HYD total dose $(0$ and $24 \mathrm{mg})$. The design for choice sessions was SR-AMP dose $\times$ COC unit dose $(0$ and $8 \mathrm{mg}) \times$ HYD unit dose $(0$ and $2 \mathrm{mg}$ ).

\section{Protocol Timeline}

Participants were stabilized on BUP $\geqslant 10$ outpatient days before in-patient admission (Friday). Actual duration of outpatient BUP stabilization was $17.1 \pm 6.2$ days 

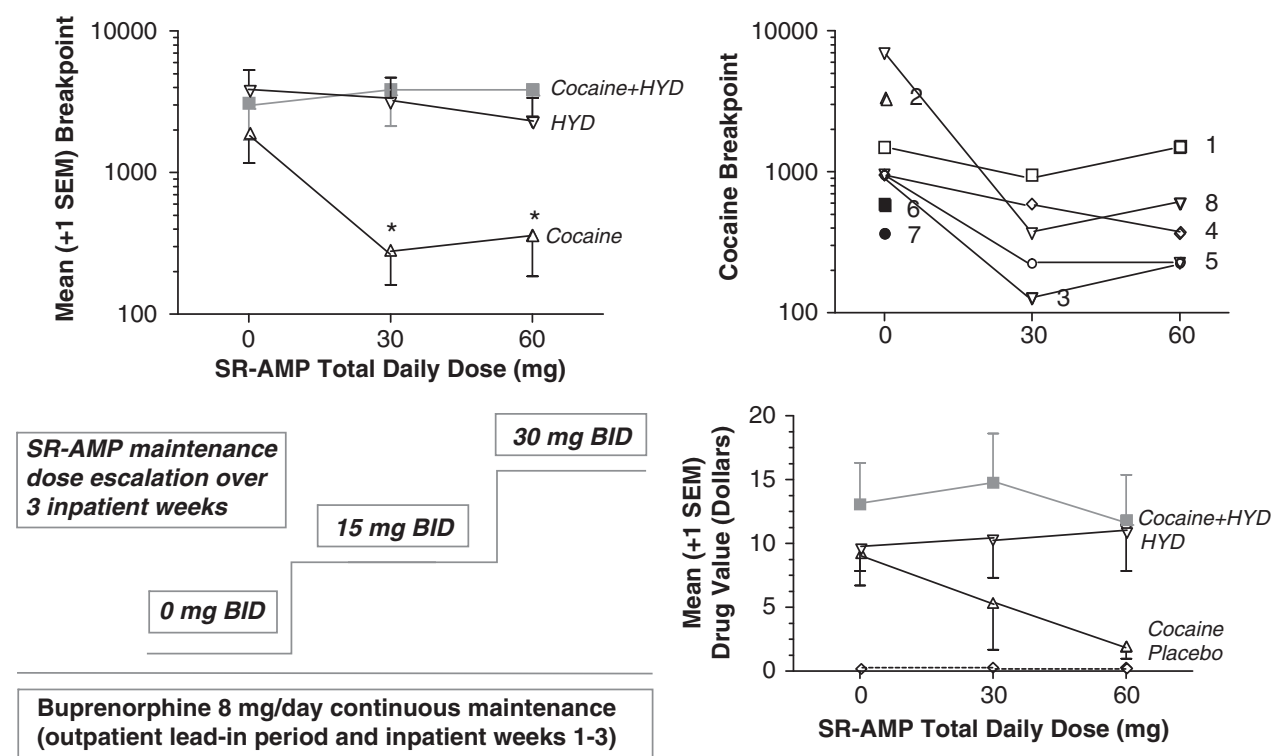

Figure I (Lower left panel) Medication dosing protocol. Buprenorphine was administered at a constant daily dose (8 mg/day) during an outpatient lead-in period and throughout the 3-week in-patient experimental period. Sustained release $d$-amphetamine (SR-AMP) doses were only administered during the in-patient period and ascended over the 3 weeks. (Upper left panel) Mean + I SEM breakpoints for hydromorphone (HYD 2-mg units), cocaine (8-mg units), and 'speedball' (cocaine 8-mg + HYD 2-mg units) at each total daily SR-AMP maintenance dose. Asterisks indicate a significant reduction in cocaine responding during both active SR-AMP doses relative to placebo SR-AMP. The twice-daily SR-AMP doses in the lower panel correspond to the SR-AMP total daily in the upper panel. (Upper right panel) Individual-subject cocaine-only breakpoints in relation to SR-AMP dose. Subject numbers correspond to those in Table 2. Three subjects (no. 2, no. 6, and no. 7; black icons at left) responded for cocaine only during placebo SR-AMP and did not respond for cocaine at all during active SR-AMP doses; for this reason, there are no connecting lines on the $\log _{10}$ y axis. (Lower right panel) Mean + I SEM money crossover points on the multiple choice procedure.

(mean $\pm \mathrm{SD}$; range, 12-28). Residential living, observation, and daily urinalysis ensured unsanctioned drug abstinence. During non-experimental periods, volunteers could engage in recreational activities, for example, reading, listening to music, riding an exercise bicycle, watching movies, and telephone conversations.

Participants received the first daily SR-AMP dose (0700 hours) on the in-patient unit and were escorted to the laboratory on session days. After baseline measures (08300845 hours), HYD was injected (0900 hours), and then COC was insufflated (0915 hours). Timing of drug administration was staggered to align peak effects. Participants were asked to attend to drug effects because they could later choose units of drug or money. Subjective and physiological effects were measured periodically for $3 \mathrm{~h}$ after HYD administration. After lunch (1200-1220 hours), the second SR-AMP daily dose was administered (1225 hours). The drug vs money choice task was conducted from 1230 to 1530 hours. After post-drug safety monitoring, participants returned to the in-patient unit.

\section{Drug Administration}

Buprenorphine. Participants received BUP 8-mg tablets during initial outpatient and in-patient periods or, during detoxification, multiple 2-mg tablets and matching placebos (Subutex; Reckitt-Benckiser, Hull, UK; from Research Triangle Institute, Research Triangle Park, NC). Staff supervised each participant holding BUP tablet(s) sublingually until dissolved. During the in-patient period, participants received BUP $8 \mathrm{mg} / \mathrm{day}$ at 2000 hours. This dose was chosen to suppress opioid withdrawal symptoms, while enabling HYD to surmount BUP blockade.
Sustained release d-amphetamine. Each SR-AMP 15-mg spansule (Dexedrine Sulfate ER, AmeriSource Bergen Corp., Williamston, MI) was placed inside an opaque size-0 capsule, and each placebo capsule contained lactose. The participant's mouth was inspected to ensure that capsules were swallowed. During week 1 (Saturday-Friday), the SRAMP daily dose was $0 \mathrm{mg}$ (0 $\mathrm{mg}$ twice a day); during week 2 (Saturday-Friday), the daily dose was $30 \mathrm{mg}$ ( $15 \mathrm{mg}$ twice a day); and during week 3 (Saturday-Friday), the daily dose was $60 \mathrm{mg}$ ( $30 \mathrm{mg}$ twice a day).

Hydromorphone. Doses of HYD (Dilaudid-HP in $50 \mathrm{mg} /$ $5 \mathrm{ml}$ ampoules; purchased from the hospital pharmacy) were injected (constant volume $=2.4 \mathrm{ml}$ ) into the deltoid muscle. Doses administered were $0 \mathrm{mg}(2.4 \mathrm{ml}$ physiological saline), $24 \mathrm{mg}$, or the response-contingent dose.

Cocaine. Cocaine $\mathrm{HCl}$ powder (from Research Triangle Institute) was prepared in $100 \mathrm{mg}$ constant-volume doses for insufflation. Placebo contained $4 \mathrm{mg}$ COC and $96 \mathrm{mg}$ lactose; active sampling doses were $100 \mathrm{mg}$ COC without lactose. Response-contingent COC doses contained the earned COC dose with the complement being lactose. Participants insufflated powder from a small plastic cup through a $65-\mathrm{mm}$ plastic straw.

\section{Measures}

Urinalysis. Urine samples were read for the presence of opioids, cocaine metabolites, benzodiazepines $(\geqslant 300 \mathrm{ng} / \mathrm{ml})$, amphetamines $(\geqslant 1000 \mathrm{ng} / \mathrm{ml})$, barbiturates $(\geqslant 200 \mathrm{ng} / \mathrm{ml})$, and THC metabolites ( $\geqslant 50 \mathrm{ng} / \mathrm{ml})$. To maintain doubleblind dosing during the in-patient stay, amphetamines were 
not tested and, following session days (Wednesday, Thursday, and Friday), opioids and cocaine were not tested.

Weekly baseline symptoms. The third afternoon (Monday 1530 hours) at each SR-AMP dose, participants completed the Cocaine Selective Severity Assessment (CSSA; Kampman et al, 1998), an 18-item measure of cocaine abstinence signs/symptoms; Epworth Sleepiness Scale (ESS; Johns, 1991), a 10-item measure of daytime sleepiness; and Beck Depression Inventory-II, a 21-item measure of depression symptoms (Beck et al, 1996).

Subjective effects and vital signs. Vital signs (respiration rate, oxygen saturation, heart rate (HR), and blood pressure (BP)) and subjective effects were assessed $-0.5,0.5,0.75,1$, $1.5,2,2.5$, and $3 \mathrm{~h}$ relative to HYD administration. Postdrug absolute peaks were used to simplify analyses. These scores reflect combined effects of SR-AMP, COC, and HYD, which provide safety data that are clinically relevant and easily interpreted.

Heroin craving was assessed with a 10-item (S Tiffany, personal communication, 1999) Heroin Craving Questionnaire (Schuster et al, 1995). Cocaine craving was measured with a 10-item (Sussner et al, 2006) Cocaine Craving Questionnaire (Tiffany et al, 1993). Seven visual analog scale (VAS, 0-100) drug-effect ratings were obtained: Any Effect, Good Effect, Bad Effect, High, Liking, Stimulated, Sedated, and Want Drug Again. Opioid agonist (16 items) and withdrawal symptoms (16 items) were assessed with an Opioid Symptom Questionnaire (Schuster et al, 1995). Psychostimulant effects were assessed with the 21-item Stimulant-Sensitive Adjective Rating Scale (SSARS; Rush et al, 1999). Participants completed the 49-item Addiction Research Center Inventory (ARCI; Jasinski, 1977; Martin et al, 1971), which has five subscales: morphine-benzedrine group (MBG, euphoria); pentobarbital, chlorpromazine, alcohol group (PCAG, sedation); lysergic acid diethylamide group (LSD, dysphoria and somatic effects); and benzedrine group and amphetamine scales (BG and A, amphetamine-like).

A modified multiple choice procedure (MCP; Griffiths et al, 1993) was used. At $3 \mathrm{~h}$ after sampling each drug combination, the participant made choices between that dose and 44 different money amounts from US $\$ 0.25$ to US $\$ 25.00$. The amount at which the participant switched from choosing drug to money is a measure of drug monetary value.

Drug reinforcement. During choice sessions, a 12-trial PR procedure was used. Across trials within session, response requirements for drug and money options increased independently in an exponential function, with fixed ratios (FRs) of 125, 225, 365, 590, 950, 1500, 2300, 3415, 4915, 6875, 9375, and 12500. Participants were instructed they did not have to respond at all. Thus, choosing one alternative would not mean avoidance of the other option.

Measures of drug reinforcing efficacy included total number of drug choices, breakpoint (highest FR completed), and cumulative drug responding (all FRs completed plus incomplete responding when the 3-h session terminated).
These measures reflect responding before receipt of drug (ie, seeking) rather than self-administration. Although the participant self-administered the earned cocaine dose, a research nurse administered the earned hydromorphone injection (technically, not self-administration).

Money reinforcement. Participants could earn US $\$ 40$ nightly for living on the in-patient unit and US $\$ 2$ per money choice in each of the 12 sessions. Payments (by check) were disbursed on the day of discharge (all choice earnings plus half of in-patient nights), and the remainder (other half of in-patient nights) was given in two payments during BUP dose tapering.

\section{Data Analyses}

Sampling. Post-drug $(0.5-3.0 \mathrm{~h})$ peak, subjective and physiological effects were analyzed using SR-AMP dose $(0,30$, and $60 \mathrm{mg} /$ day $) \times$ COC dose $(4$ and $100 \mathrm{mg}) \times$ HYD dose $(0$ and $24 \mathrm{mg})$ repeated measures Analyses of variance (ANOVAs). Huynh-Feldt adjusted $p$ values were used for sphericity violations. Minimum level of significance was $p<0.05$.

Choice. ANOVAs examined effects of SR-AMP dose (0, 30, and $60 \mathrm{mg} /$ day), COC unit dose ( 0 and $8 \mathrm{mg}$ ), and HYD unit dose $(0$ and $2 \mathrm{mg})$ on drug-reinforced responding. Planned two-way SR-AMP dose $(0,30$, and $60 \mathrm{mg} /$ day $) \times$ HYD unit dose $(0$ and $2 \mathrm{mg})$ ANOVAs isolating only the active cocaine dose conditions were used to determine whether SR-AMP selectively reduced seeking for cocaine or speedball. Breakpoint and cumulative responding measures were $\log _{10}$ transformed for ANOVAs, but untransformed data are presented for clarity in Table 1 and Figure 1. When participants did not choose drug at all, $\log _{10}$ data were assigned a value of 0.1 .

\section{RESULTS}

\section{Participant Characteristics}

Sixteen volunteers were enrolled; all were physically dependent on opioids and all but one also met the criteria for cocaine dependence (the other for cocaine abuse). Three discontinued before starting BUP dosing. Thirteen were admitted to the in-patient unit and began the first week of sessions; of these, two dropped out during week 1 while receiving placebo SR-AMP (one had a family problem, one felt confined on the in-patient unit), and one was excluded because he did not differentiate placebo from active COC. Two participants were discontinued owing to adverse events that were possibly/probably related to SR-AMP. One individual (39 years old male) experienced nausea and vomiting shortly after admission (placebo SR-AMP) and, after 3 days on SR-AMP $30 \mathrm{mg} / \mathrm{day}$, reported feeling depressed; SR-AMP was stopped and, after overnight observation, the participant was cleared for discharge. Another individual (24 years old male) experienced a moderately severe headache (unresponsive to acetaminophen and ibuprofen), photophobia and tachycardia (baseline HR >90 b.p.m.) and received brief care in the emergency room. These signs and symptoms quickly 
resolved for both individuals once their participation was terminated. Data from these individuals are excluded from this report, other than for safety discussion.

Table 2 lists individual and summary (mean $\pm 1 \mathrm{SD}$; median) demographic and substance use characteristics of the eight study completers. These individuals (six white males and 1 white female (who all met the criteria for cocaine dependence) and one African-American female (who met the criteria for cocaine abuse)) were on average $37.0 \pm 7.0$ years old (range: 24-46), had a high school education (11.6 \pm 1.2 years, range: $10-13$ ), and were in the normal range for weight (161 $\pm 23 \mathrm{lbs}$, range: $127-196)$ and body mass index $(24.6 \pm 2.5 \mathrm{lbs}$, range: $21.8-28.1)$. They reported extensive histories of daily heroin use (mostly IV) and regular cocaine use (mostly smoked 'crack'). All but one individual spent more income on heroin than cocaine. All participants smoked cigarettes daily $(17.1+5.7$, range: 6-21), and during the past 30 days, two had smoked marijuana, and one had used benzodiazepines. All participants provided urine samples that were positive for opioids (heroin) and cocaine metabolites at screening and during the initial outpatient BUP stabilization period.

\section{Weekly Baseline Symptoms}

Relative to placebo SR-AMP maintenance, cocaine abstinence (CSSA total) scores trended to be lower during maintenance on 30 and $60 \mathrm{mg} /$ day SR-AMP $(\mathrm{Ms} \pm \mathrm{SDs}=$ 12.5. $\pm 2.6,6.5 \pm 1.5$, and $9.0 \pm 2.4$, respectively), $\mathrm{F}(2,14)=$ 3.48, $p<0.06$. Relative to placebo SR-AMP, daytime sleepiness (ESS total) scores were slightly lower during SR-AMP 30 and $60 \mathrm{mg} / \mathrm{day}$ (Ms $\pm \mathrm{SDs}=5.6 \pm 1.2,3.9 \pm 0.8$, and $4.1 \pm 0.9$, respectively), but this was also not significant, $\mathrm{F}(2,14)=3.10, p<0.11$. Beck depression symptom total scores were low overall (mean $\approx 5)$ and did not differ as a function of SR-AMP dose $(p=0.88)$.

\section{Subjective and Physiological Effects (Drug Sampling)}

Table 3 provides descriptive statistics (means \pm 1 SEMs), and Table 4 provides overall ANOVA summaries for postdrug peak subjective and physiological effects during morning sampling sessions.

Stimulant effects. SSARS scores were significantly increased by COC and HYD. Relative to placebo maintenance, SR-AMP 30 and $60 \mathrm{mg} /$ day similarly decreased SSARS scores (see Figure 2).

Opioid effects. As predicted, opioid withdrawal scores were low (peaks <6) throughout the study owing to BUP maintenance. HYD did not alter opioid withdrawal scores. Opioid withdrawal scores showed a trend to be increased by COC, and a trend to be reduced by SR-AMP. As predicted, opioid agonist scores were significantly greater following HYD, and showed a similar trend to be increased following cocaine administration. SR-AMP did not alter opioid agonist scores.

Drug craving. Cocaine craving scores were generally in the low-to-moderate intensity range. Cocaine craving was significantly increased by COC administration, and by 
Table 2 Participant Characteristics

\begin{tabular}{|c|c|c|c|c|c|c|c|c|c|c|}
\hline \multirow{2}{*}{ Subject } & \multirow{2}{*}{ Race } & \multirow{2}{*}{ Sex } & \multicolumn{3}{|c|}{ Pattern of heroin use } & \multicolumn{4}{|c|}{ Pattern of cocaine use } & \multirow{2}{*}{$\begin{array}{l}\text { Other past } 30 \text {-day } \\
\text { substance use }\end{array}$} \\
\hline & & & Years & Route & $\begin{array}{l}\text { US\$ spent } \\
\text { weekly }\end{array}$ & Years & Route & $\begin{array}{l}\text { US\$ spent } \\
\text { weekly }\end{array}$ & $\begin{array}{c}\text { No. past } \\
30 \text { days use }\end{array}$ & \\
\hline I & W & $\mathrm{F}$ & 10 & IV & 210 & 3 & SM & 35 & 30 & \\
\hline 2 & W & M & 9 & IV & 210 & 13 & SM & 50 & 6 & \\
\hline 5 & W & M & 10 & IV & 280 & 18 & SM & 50 & 25 & \\
\hline 6 & W & M & 16 & IV & 50 & 16 & IV & 20 & 10 & ALC ( I day $\times 6$ drinks $)$ \\
\hline 7 & W & M & 10 & IV & 140 & 12 & SM & 350 & 15 & MJ (2 days), BD (4 days) \\
\hline 8 & W & M & 2 & IV & 210 & 4 & SM & 100 & 30 & MJ (3 days) \\
\hline Mean & & & 10.6 & & 164 & 14.1 & & 82 & 17.3 & \\
\hline
\end{tabular}

Notes: Patterns of heroin and cocaine use are described in terms of duration of regular use (years), current primary route of use (intravenous (IV), intranasal (IN), or smoked (SM)), amount of money (US\$) spent per week on each drug (which may differ from the amount of drug consumed) and, for cocaine, the number of self-reported cocaine use days during the 30 days before screening. Other substance use reflects self-reported (ALC) and/or urinalysis evidence of marijuana (MJ) or benzodiazepine (BD) used during the 30 days before screening or during the 2-week outpatient buprenorphine lead-in period. See text for additional details on participant characteristics.

HYD administration. Relative to placebo, SR-AMP $30 \mathrm{mg} /$ day (but not $60 \mathrm{mg} /$ day) showed a trend to decrease cocaine craving. Heroin craving scores were generally in the moderate intensity range. Cocaine administration significantly increased heroin craving; however, HYD did not significantly affect heroin craving. SR-AMP produced a significant, dose-dependent reduction in heroin craving scores across all drug combinations.

Visual analog scales. Cocaine and HYD each significantly increased ratings of 'any drug effect', 'good drug effect', and 'high', and speedball produced significantly greater increases in these ratings. SR-AMP significantly decreased these VAS ratings of any drug effect, good drug effect, and high.

Cocaine and HYD each significantly increased VAS ratings of 'drug liking', 'stimulated', and 'want drug again' (see Figure 2); however, speedball did not increase these ratings further. SR-AMP significantly decreased ratings of drug liking and stimulated.

HYD significantly increased VAS ratings of 'sedated'. Cocaine produced a trend toward lower sedation ratings. SR-AMP produced a modest, dose-related increase in sedation ratings in the presence of cocaine, while slightly decreasing sedation ratings (relative to modest levels during placebo SR-AMP) in the absence of cocaine.

Ratings of 'bad drug effect' were significantly lower in the presence of HYD. Neither COC nor SR-AMP altered these ratings.

ARCI scales. Cocaine and HYD each significantly increased scores on the ARCI-MBG (euphoria) and ARCI-A scales. SR-AMP did not significantly alter these ratings. Scores on the ARCI-PCAG (sedation) scale were significantly higher in all active drug conditions relative to placebo. SR-AMP did not significantly alter these ratings. SR-AMP significantly reduced ARCI-BG scale scores, but only in the presence of cocaine. HYD did not significantly alter these scores. Cocaine significantly increased scores on the ARCILSD scale. Neither HYD nor SR-AMP significantly altered these ratings.

MCP drug value. Overall, drug value (US\$ crossover point in the MCP) relative to placebo was significantly greater for COC and for HYD. In the planned hypothesis test, speedball was rated to be worth significantly more than $\mathrm{COC}$ alone. However, SR-AMP did not significantly reduce speedball or COC drug value using this measure (see Figure 1 lower right panel).

Vital signs. HYD significantly reduced trough respiration rate and oxygen saturation; neither measure was influenced by COC or SR-AMP.

Cocaine significantly increased HR. SR-AMP increased HR by several beats per min, significantly more so in the presence of hydromorphone. SR-AMP did not potentiate cocaine tachycardia, but increased HR in the absence of cocaine (see Figure 3).

Cocaine significantly increased systolic and diastolic BP. SR-AMP did not enhance COC-induced increases in systolic and diastolic BP, but significantly increased systolic and diastolic BP by several $\mathrm{mm} \mathrm{Hg}$ in the absence of cocaine (see Figure 3).

\section{Drug Reinforcing Effects (Choice PR)}

Tables 1 and 4 provides descriptive statistics (means \pm 1 SEMs) and overall ANOVA summaries for all measures of drug reinforcing efficacy.

Drug choices. In the overall analysis, the number of drug choices was significantly greater for all drug conditions relative to placebo, and there was a significant main effect for HYD. SR-AMP significantly reduced drug choices. In the 
Table 3 Peak Post-Drug Subjective and Physiological Responses during Sampling Sessions ${ }^{a}$

\begin{tabular}{|c|c|c|c|c|c|c|c|c|c|c|c|c|}
\hline \multirow{2}{*}{ Measure (range of scores) ${ }^{b}$} & \multicolumn{4}{|c|}{ SR-AMP $0 \mathrm{mg} /$ day (placebo) } & \multicolumn{4}{|c|}{ SR-AMP $30 \mathrm{mg} /$ day } & \multicolumn{4}{|c|}{ SR-AMP $60 \mathrm{mg} / \mathrm{day}$} \\
\hline & Pla & Hyd & Coc & d & la & Hyd & Coc & d & la & yd & :oc & d \\
\hline -84) COC+, HYD+, AMP- $^{-1}$ & $3(1.0)$ & & ) & $17.6(4.5)$ & $1.5(0.8)$ & & & & ) & ) & & ) \\
\hline Cocaine craving questionnaire $(10-70)^{\mathrm{COC}+, \text { HYD+ }}$ & $23.8(5.2)$ & $27.1(4.1)$ & $39.3(4.3)$ & $38.9(4.7)$ & $18.6(3.7)$ & $23.1(5.2)$ & $22.1(5.5)$ & $31.4(6.4)$ & | $8.0(3.6)$ & $19.4(3.8)$ & $27.8(5.9)$ & $40.1(9.2)$ \\
\hline Heroin craving questionnaire $(10-70)^{C O C+}$, AMP- & $38.5(6.7)$ & $41.5(6.4)$ & $44.5(7.2)$ & $46.0(5.9)$ & $34.5(5.8)$ & $42.4(5.8)$ & $39.4(7.0)$ & $40.5(5.6)$ & $27.0(5.4)$ & $35.4(5.1)$ & $31.8(6.2)$ & $33.3(5.4)$ \\
\hline Opioid withdrawal scale (0-64) & $2.6(0.8)$ & $2.3(0.9)$ & $4.8(1.7)$ & $5.5(1.9)$ & $1.9(0.9)$ & $1.3(0.9)$ & $4.0(1.8)$ & $2.5(1.4)$ & $1.4(0.6)$ & $1.5(0.9)$ & $2.8(0.9)$ & $3.1(1.2)$ \\
\hline Opioid agonist scale $(0-64)^{\mathrm{HYD}+}$ & $7.8(1.3)$ & $17.0(2.6)$ & $10.8(2.3)$ & $17.3(2.7)$ & $7.4(0.9)$ & $16.5(1.7)$ & $9.8(1.9)$ & $16.3(1.3)$ & $7.0(0.9)$ & $14.6(1.8)$ & $8.1(1.1)$ & $17.4(2.1)$ \\
\hline Any drug effect VAS $(0-100)^{\mathrm{COC}+}$ & $5.1(2.5)$ & $67.0(10.2)$ & $50.8(10.1)$ & $79.8(5.5)$ & $7.9(6.6)$ & $59.5(8.4)$ & $29.8(7.4)$ & $65.3(7.5)$ & $1.4(0.7)$ & $47.9(9.1)$ & $29.5(6.9)$ & $62.5(9.2)$ \\
\hline Good drug effect VAS $(0-100)^{C O C+}$, HYD+, COC $\times$ HYD, AMP- & $6.1(2.7)$ & $74.9(6.5)$ & $49.9(12.1)$ & $75.9(6.5)$ & $4.4(3.2)$ & $62.0(8.4)$ & $24.3(8.5)$ & $70.9(5.6)$ & $1.8(0.7)$ & $52.8(8.9)$ & $22.6(6.9)$ & $70.4(7.3)$ \\
\hline Bad drug effect VAS (0-100) HYD- & $28.6(15.5)$ & $12.8(6.7)$ & $19.8(9.5)$ & $10.8(4.5)$ & $7.3(6.3)$ & $16.3(12.1)$ & $25.0(11.5)$ & $3.8(2.4)$ & $1.4(0.6)$ & $2.5(0.9)$ & |3.1 (8.1) & $9.5(4.4)$ \\
\hline Drug high VAS $(0-100)^{C O C+,}$ HYD+, AMP-, AMP $\times$ COC & $5.1(2.4)$ & $64.5(10.1)$ & $51.3(10.2)$ & $76.3(6.3)$ & $4.9(3.7)$ & $54.4(10.2)$ & $20.6(7.2)$ & $63.5(8.1)$ & $1.4(0.7)$ & $47.6(10.1)$ & $21.8(6.3)$ & $62.1(10.9)$ \\
\hline Drug liking VAS $(0-100)^{C O C+, ~ H Y D+, ~ A M P-~}$ & I $1.6(5.7)$ & $73.4(5.4)$ & $47.8(11.2)$ & $77.6(7.1)$ & $6.0(3.2)$ & $62.4(7.2)$ & $20.0(6.0)$ & $69.0(5.7)$ & $4.4(2.6)$ & $53.8(9.0)$ & $23.5(6.5)$ & $70.6(7.5)$ \\
\hline Stimulated VAS $(0-100)^{\mathrm{COC}+, \text { HYD+, AMP- }}$ & $5.6(2.6)$ & $33.0(13.1)$ & $49.9(11.1)$ & $65.9(\mid 3.1)$ & $2.5(1.4)$ & $23.0(10.7)$ & $22.0(8.3)$ & $47.3(9.4)$ & $1.9(0.8)$ & $21.8(10.0)$ & $22.0(7.5)$ & $36.6(11.5)$ \\
\hline Sedated VAS $(0-100)^{H Y D+}$, AMP $\times$ COC, AMP $\times$ COC $\times$ HYD & $3.4(1.3)$ & $49.4(12.8)$ & $4.4(1.6)$ & $12.9(4.2)$ & $7.3(6.3)$ & $41.3(11.8)$ & $4.6(2.1)$ & $31.0(11.3)$ & $2.1(0.8)$ & $33.0(12.6)$ & $6.6(5.5)$ & $38.5(13.1)$ \\
\hline Want drug again VAS $(0-100)^{\mathrm{COC}+\text {, HYD+, AMP- }}$ & $24.3(12.2)$ & $64.9(7.3)$ & $51.9(12.3)$ & $75.0(8.2)$ & $6.1(3.5)$ & $46.9(10.0)$ & | $5.0(5.7)$ & $61.6(6.3)$ & $2.3(0.8)$ & $48.9(11.6)$ & $14.9(6.2)$ & $56.8(10.8)$ \\
\hline ARCI MBG scale $(0-16)^{\mathrm{COC}+, \text { HYD+ }}$ & $3.0(0.9)$ & $6.6(1.6)$ & $5.0(1.4)$ & $7.4(1.4)$ & $2.9(0.9)$ & $5.4(1.5)$ & $3.4(0.9)$ & $6.9(1.3)$ & $2.9(0.8)$ & $7.1(1.7)$ & $3.0(0.9)$ & $6.5(1.5)$ \\
\hline ARCI BG scale $(0-13)^{A M P} \times C O C$ & $6.6(0.7)$ & $6.4(0.5)$ & $7.4(0.9)$ & $8.5(0.7)$ & $7.0(0.9)$ & $6.8(0.7)$ & $6.9(0.7)$ & $7.3(0.9)$ & $7.4(0.8)$ & $7.4(0.9)$ & $7.0(0.8)$ & $7.5(1.0)$ \\
\hline ARCl A scale $(0-1 \mid)^{\text {COC+, HYD+ }}$ & $2.9(0.5)$ & $4.8(0.6)$ & $4.8(0.8)$ & $6.0(0.7)$ & $3.0(0.7)$ & $4.3(0.8)$ & $3.6(0.8)$ & $4.9(1.0)$ & $3.4(0.7)$ & $5.3(1.2)$ & $3.8(0.8)$ & $5.6(1.1)$ \\
\hline ARCI PCAG scale $(0-15)$ COC $\times$ HYD & $3.8(0.3)$ & $6.4(0.8)$ & $4.4(0.5)$ & $4.9(0.5)$ & $4.8(0.9)$ & $4.4(0.6)$ & $5.1(0.6)$ & $4.9(0.7)$ & $3.6(0.3)$ & $4.5(0.5)$ & $4.9(1.1)$ & $5.3(0.7)$ \\
\hline ARCI LSD scale $(0-14)^{\mathrm{COC}+}$ & $4.1(0.8)$ & $4.4(0.9)$ & $6.9(1.4)$ & $6.5(1.2)$ & $3.9(0.4)$ & $3.5(0.8)$ & $5.8(1.3)$ & $4.5(0.9)$ & $3.1(0.3)$ & $3.5(1.1)$ & $6.4(1.0)$ & $5.6(1.3)$ \\
\hline MCP drug value (US\$) ${ }^{\mathrm{COC}+, \text { HYD+ }}$ & $0.29(0.29)$ & $9.64(1.78)$ & $9.36(2.63)$ & 13.07 (3.24) & $0.29(0.29)$ & $10.25(2.93)$ & $5.38(3.68)$ & $14.79(3.82)$ & $0.29(0.29)$ & $11.07(3.22)$ & $1.93(0.93)$ & $11.79(3.58)$ \\
\hline Respiration rate (b.p.m.) ${ }^{\mathrm{HYD}-}$ & $13.6(0.7)$ & $12.5(0.7)$ & $13.9(0.6)$ & $14.3(1.0)$ & $13.6(0.5)$ & $12.4(0.7)$ & | $3.6(0.8)$ & I2.1 (0.6) & | $3.5(0.5)$ & I2.1 (0.8) & $13.5(0.6)$ & $12.9(0.6)$ \\
\hline Oxygen saturation (\%) ${ }^{\mathrm{HYD}-}$ & $96.9(0.5)$ & $94.5(0.7)$ & $97.0(0.3)$ & $95.1(0.5)$ & $96.4(0.5)$ & $94.9(0.4)$ & $96.6(0.6)$ & $95.0(0.6)$ & $96.4(0.5)$ & $94.8(0.6)$ & $97.0(0.4)$ & $94.5(0.6)$ \\
\hline Heart rate (b.p.m.) ${ }^{\mathrm{COC}+,}$ AMP-, AMP $\times \mathrm{C}$ & $72.4(4.7)$ & $73.0(3.8)$ & $90.6(4.1)$ & $96.8(6.7)$ & $81.4(2.9)$ & $80.0(3.1)$ & $87.5(5.2)$ & $90.8(4.6)$ & $82.0(3.2)$ & $90.1(3.8)$ & $87.8(3.6)$ & $94.6(4.3)$ \\
\hline Systolic BP $(\mathrm{mm} \mathrm{Hg})^{\mathrm{COC}+, \mathrm{AMP} \times \mathrm{COC}}$ & | $13.3(4.2)$ & | $18.0(5.0)$ & | $30.0(6.0)$ & $131.4(7.0)$ & । $18.4(5.9)$ & | 19.1 (5.7) & $123.4(4.5)$ & $123.4(6.3)$ & $125.4(5.1)$ & | $19.5(6.8)$ & $126.9(4.7)$ & $125.6(6.0)$ \\
\hline Diastolic BP $(\mathrm{mm} \mathrm{Hg})^{\mathrm{COC}+, \mathrm{AMP} \times \mathrm{COC}}$ & $67.5(1.7)$ & $71.6(2.7)$ & $80.3(3.2)$ & $82.5(3.7)$ & $75.0(3.2)$ & $75.3(4.0)$ & $77.9(2.5)$ & $77.8(4.1)$ & $78.0(2.9)$ & $74.6(4.1)$ & $79.6(3.0)$ & $80.3(3.6)$ \\
\hline
\end{tabular}

a Sample means ( \pm I SEM), $n=8$, except for drug value $(n=7)$

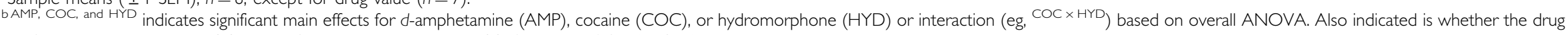
significantly increased scores $(+)$ or significantly decreased scores $(-)$. See Table 4 for ANOVA statistical details. 
Table 4 Statistical Summary of Omnibus Analyses of Variance (ANOVAs) for all Measures

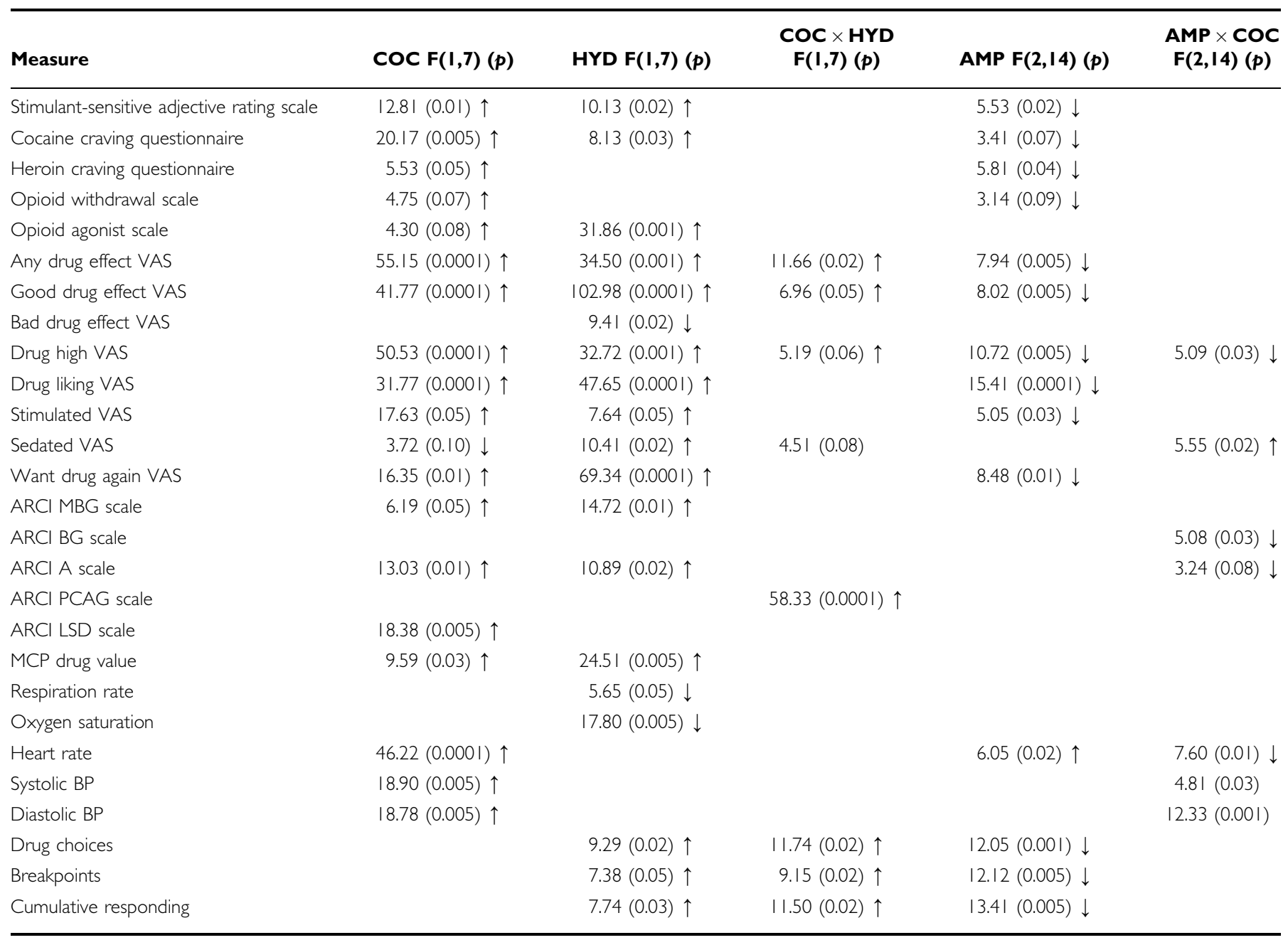

For statistical main effects (COC, HYD, AMP), $\uparrow$ represents an increase in effect, whereas $\downarrow$ represents a decrease in effect owing to the administration of the drug, relative to placebo. For interaction terms (eg, AMP $\times \mathrm{COC}$ ), $\uparrow$ indicates that, in the presence of the first drug (eg, AMP relative to placebo), administration of the second drug (eg, COC relative to placebo) increased the effect; in contrast, $\downarrow$ indicates that, in the presence of the first drug, administration of the second drug decreased the effect. When an arrow is not present, the interaction was more complex (see text for description). Blank cells indicate that there was no trend $(p>0.10)$

additional planned hypothesis test (which excluded dualplacebo and HYD-alone conditions), SR-AMP significantly reduced all choices involving cocaine, dose $\mathrm{F}(2,14)=6.46$, $p<0.03$, and more selectively reduced COC, but not speedball choices, SR-AMP $\times$ HYD F $(2,14)=4.35, p<0.04$. Participants tended to choose the speedball combination more often than cocaine alone, but this trend was not significant, HYD $\mathrm{F}(1,7)=5.04, p<0.06$.

Breakpoints. Relative to placebo, $\log _{10}$ breakpoints were significantly greater for all drug conditions, and there was a significant main effect of HYD. SR-AMP significantly reduced $\log _{10}$ breakpoints. In the additional planned hypothesis test, SR-AMP significantly reduced $\log _{10}$ breakpoints, $\mathrm{F}(2,14)=9.81, p<0.02$, and more selectively reduced COC, but not speedball breakpoints, SR-AMP $\times$ HYD $\mathrm{F}(2,14)=4.05, p<0.05$ (see Figure 1).

Cumulative responding. Relative to placebo, cumulative responding was significantly greater for all drug conditions, and there was a significant effect of HYD. SR-AMP significantly reduced cumulative responding. In the additional planned hypothesis test, SR-AMP significantly reduced cumulative responding involving all cocaine choices, $\mathrm{F}(2,14)=10.54, p<0.01$, and more selectively reduced COC, but not speedball responding, AMP $\times$ HYD $\mathrm{F}(2,14)=4.22, p<0.04$.

\section{DISCUSSION}

This study showed that when heroin/cocaine-dependent research volunteers were maintained on a moderate BUP dose $(8 \mathrm{mg} /$ day), stabilization on ascending doses of SRAMP $30 \mathrm{mg} /$ day then $60 \mathrm{mg} /$ day (relative to initial placebo) significantly reduced cocaine- but not speedball-like or opioid-seeking behavior. This is the first human laboratory study to show that SR-AMP can reduce cocaine-seeking behavior in this comorbid population.

Animal laboratory studies that have used a chronic AMP administration protocol-similar to maintenance 

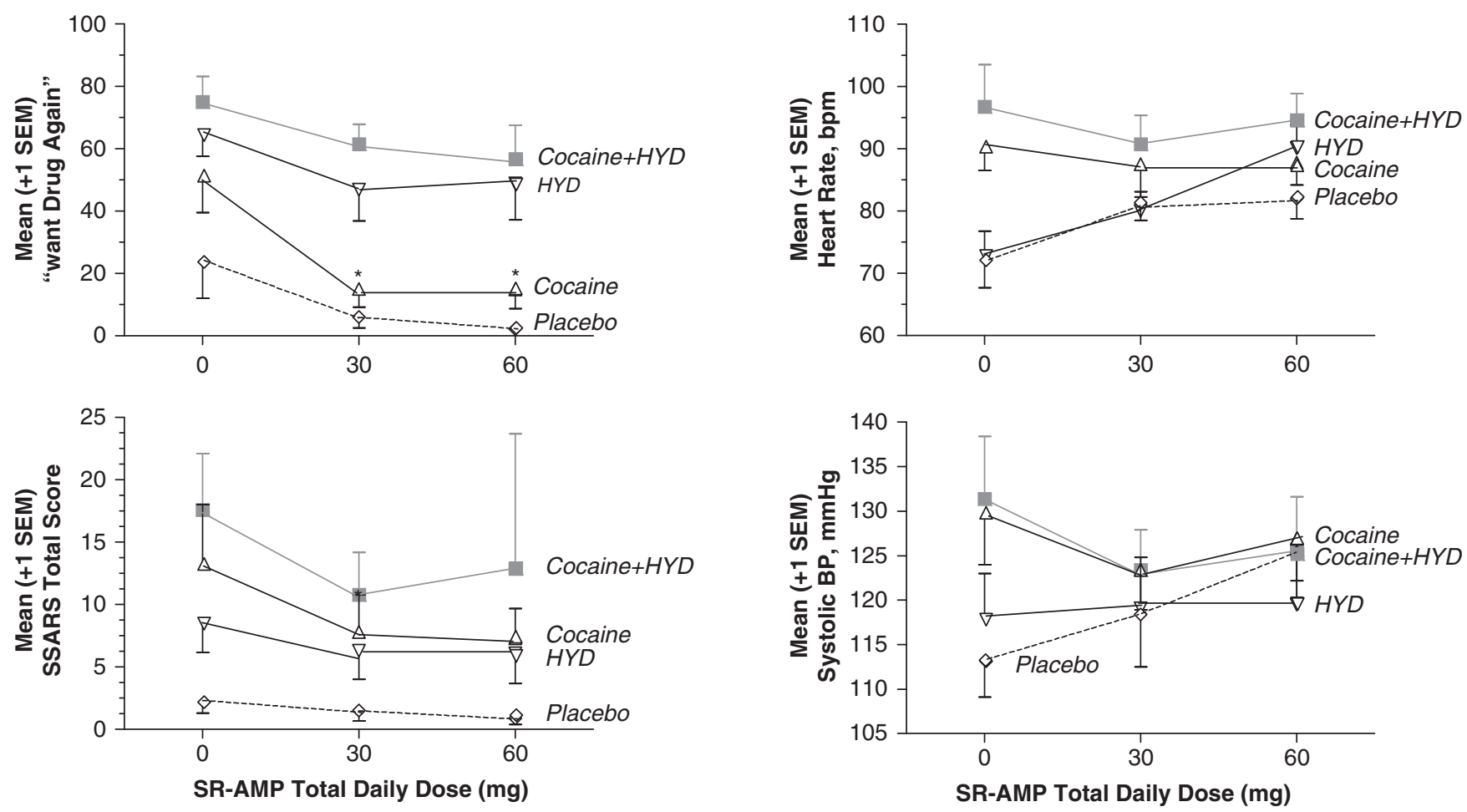

Figure 2 (Upper panel) Visual analog scale (0-100) ratings of 'want drug again'. (Lower panel) Stimulant-Sensitive Adjective Rating Scale (SSARS) total scores. Relative to the placebo condition, cocaine, hydromorphone (HYD), and speedball (cocaine + HYD) increased peak subjective effects in the absence of SR-AMP. Cocaine-induced increases in these peak effects were significantly attenuated by active SR-AMP doses.

treatment-reliably showed that AMP reduced cocainereinforced operant responding in rats (Peltier et al, 1996; Chiodo et al, 2008; Chiodo and Roberts, 2009), and cocaine $v s$ food choice in rhesus monkeys (Negus, 2003; Negus and Mello, 2003a, b). In a human laboratory study (Rush et al, 2009), short-term (3-5 days) maintenance on SR-AMP (15 and $30 \mathrm{mg} /$ day $v s$ placebo) significantly reduced subjective and physiological effects of intranasal cocaine (at cumulative doses up to $94 \mathrm{mg}$ ). A recent follow-up study with nine cocaine-dependent individuals showed that maintenance on SR-AMP ( $40 \mathrm{mg} /$ day $v s$ placebo) modestly, but significantly reduced the number of choices (up to 6 units available at $45 \mathrm{~min}$ intervals) of an intermediate cocaine unit dose (20 mg), but not a lower $(10 \mathrm{mg})$ or higher $(30 \mathrm{mg})$ unit dose (Rush et al, 2010). Finally, two placebo-controlled, randomized clinical trials showed that SR-AMP doses ranging from 15 to $30 \mathrm{mg}$ twice a day $(30-60 \mathrm{mg} /$ day) significantly increased treatment retention, whereas only SR-AMP $60 \mathrm{mg} /$ day significantly reduced cocaine use (Grabowski et al, 2001, 2004a). Importantly, the combined use of MTD $(1.1 \mathrm{mg} / \mathrm{kg} /$ day) and SR-AMP (up to $60 \mathrm{mg} /$ day) was effective in one clinical trial (Grabowski et al, 2004a); however, its ability to reduce speedball-maintained responding has not yet been studied in the human laboratory setting. This study's finding is consistent with the above literature in showing that SR-AMP (within a similar dose range) significantly reduces cocaine-reinforced responding. This scientific demonstration is important because it contributes evidence toward the predictive validity of

Figure 3 (Upper panel) Heart rate. (Lower panel) Systolic blood pressure. Relative to the placebo condition, cocaine and speedball (cocaine + HYD) increased peak cardiovascular effects in the absence of SR-AMP. In the placebo and HYD conditions, active SR-AMP doses modestly but significantly increased heart rate and blood pressure; however, SR-AMP did not potentiate cocaine- and speedball-induced increases in these cardiovascular responses.

laboratory-based medication screening for cocaine dependence (Comer et al, 2008; Herin et al, 2010). Other than this collection of SR-AMP findings, the only other instance of concordance between human laboratory and clinical trial efficacy findings for an anti-cocaine medication has occurred with modafinil (Dackis et al, 2005; Hart et al, 2008; Anderson et al, 2009).

Our expectation for SR-AMP, as an agonist replacement approach, is that relatively higher doses should reduce cocaine reinforcement just as relatively higher BUP doses should reduce $\mu$-opioid reinforcement. Attenuating the self-administration of cocaine/opioid combinations is a desirable, but not guaranteed, consequence of adequate medication combination doses because the reinforcing effects of these abused drugs are mediated by partially distinct neurobiological mechanisms. The results of this study indicate that SR-AMP did not significantly alter drug seeking for HYD, either alone or combined with cocaine. This occurred during maintenance on a moderate BUP dose (8 mg/day), under which condition HYD serves as a reinforcer (Greenwald and Hursh, 2006; Greenwald and Steinmiller, 2009; Greenwald, 2010).

This study's design did not provide a complete test of the dual-agonist replacement hypothesis. Specifically, we used a single moderate BUP dose to suppress opioid withdrawal while enabling HYD $\mu$-agonist effects to serve as a positive control condition. A full test of the hypothesis would have used additional higher BUP doses. Under our test conditions, SR-AMP doses did not significantly alter the 
reinforcing efficacy of HYD or the speedball analog. This pattern indicates that the reduction in cocaine-seeking behavior was pharmacologically specific and that the laboratory model was reliable (ie, subjects consistently responded for HYD and speedball across protocol weeks). Previous human laboratory studies have shown that higher BUP maintenance doses (16-32 mg/day) significantly decrease opioid seeking (Greenwald et al, 2002; Comer et al, 2005). Thus, our working hypothesis - which requires further research - is that increasing the BUP dose in combination with SR-AMP could decrease the reinforcing efficacy of $\mu$-opioids and cocaine individually and, potentially, opioid/cocaine combinations. Such an outcome would also be consistent with the results of one clinical trial showing that very high BUP doses (24-32 mg/day) alone could reduce but not eliminate cocaine use (Montoya et al, 2004). Experimental confirmation of this hypothesis could point the way toward a dual agonist-replacement approach for this polydrug-using population. Although concerns about the safety of, and compliance with, a dualpharmacotherapy regimen poses challenges, the benefit/cost ratio of this approach is favorable given the disproportionate harms in this population.

Interestingly, the Rush et al (2009) study did not find a significant effect of SR-AMP on intranasal cocaine money value based on crossover points in the MCP or ratings of 'willing to pay for' cocaine. However, mean cocaine value in the placebo SR-AMP condition of this study, which used a hypothetical, non-reinforced MCP (US\$9.36; Table 3), was considerably higher than cocaine's value in the Rush et al (2009) study ( $\approx$ US $\$ 2.00)$. In our planned hypothesis test that included the cocaine and speedball conditions, SRAMP did not significantly reduce cocaine money value. This finding that SR-AMP significantly decreases cocaine-seeking behavior, but not its monetary value, suggests that the choice PR procedure may be a more sensitive assay under these conditions. The lack of a significant SR-AMP effect on cocaine value observed by Rush et al (2009) could have been owing to a floor effect in that subject sample. The inconsistent effect of SR-AMP on reducing cocaine choices across unit doses (Rush et al, 2010) could, as those authors explain, be related to the use of a potentially less-sensitive discrete choice procedure.

These data also show that SR-AMP (1) partially attenuated negative baseline symptoms (possibly related to shortterm cocaine abstinence while living on the in-patient unit), and (2) significantly attenuated subjective responses to cocaine. First, independent of the test drug (HYD or cocaine) condition, SR-AMP generally decreased ratings of stimulation (ie, dose main effect for total scores on the SSARS, and VAS 'stimulated'). SR-AMP also decreased the 'want drug again' VAS rating and, for reasons that are not entirely clear, total scores on the Heroin Craving Questionnaire. SR-AMP tended to reduce baseline cocaine abstinence symptoms on the CSSA, although this was not statistically significant. SR-AMP did not significantly increase baseline opioid withdrawal symptoms (which were low) during BUP maintenance, nor did it increase ratings of 'bad drug effect' or sedation. Second, several questionnairebased indices of cocaine drug effect were reduced during active SR-AMP treatment. Cocaine craving, which increased after cocaine sampling doses, was attenuated during maintenance on SR-AMP $30 \mathrm{mg} /$ day but not $60 \mathrm{mg} /$ day. SR-AMP treatment significantly attenuated cocaine-induced ratings on the ARCI-BG scale, and significantly attenuated cocaine-induced ratings of 'good drug effect', 'high', and 'liking'.

The safety profile of SR-AMP in combination with BUP was also evaluated. SR-AMP modestly increased baseline HR and BP in the absence of cocaine or HYD, but SR-AMP did not significantly potentiate the cardiovascular effects of cocaine. These findings are consistent with data from Rush et al (2010), and suggest that SR-AMP may be generally safe, especially when careful screening precautions are implemented. On the other hand, two participants were excluded for adverse events at the start of in-patient week 2, which coincided with induction onto the first active dose of SRAMP (30 mg/day). One participant experienced temporary nausea/vomiting soon after admission (placebo SR-AMP) and continued, but was later discharged upon reporting feelings of depression after 3 days on SR-AMP $30 \mathrm{mg} /$ day. The other participant exhibited tachycardia (HR $>90$ b.p.m.) and reported headache (unresponsive to acetaminophen and ibuprofen) and photophobia once SRAMP $30 \mathrm{mg} /$ day was started. These signs and symptoms for both individuals quickly resolved once participation was terminated. This also emphasizes the virtue of dose escalation in laboratory studies and for potential clinical use (see Herin et al, 2010, for a discussion of risk minimization).

There is presently no basis on which to expect a pharmacokinetic interaction between SR-AMP and BUP. First, these medications are primarily metabolized by different pathways. In humans, the primary mode of AMP metabolism occurs through deamination to phenylacetone (Green et al, 1986), with 4-hydroxylation by cytochrome P450 (CYP) 2D6 as a minor pathway (Bach et al, 1999), which differs from rats (Tomkins et al, 1997). In contrast, BUP is metabolized to nor-BUP by CYP3A4 (eg, Kobayashi et al, 1998; Moody et al, 2002), with additional involvement of CYP2C8 (Moody et al, 2002). Second, while there is in vitro evidence that BUP can weakly inhibit CYP2D6catalyzed reactions (eg, Umehara et al, 2002; Zhang et al, 2003), BUP concentrations used in those studies substantially differed from therapeutic concentrations. BUP is therefore unlikely to have a major effect in altering clearance of AMP.

These data suggest that, among cocaine/heroin-dependent individuals, precautions are necessary to avert potential side effects of SR-AMP. All participants underwent extensive medical and psychiatric screening, and SR-AMP doses were administered in ascending order (which may confound the results) to minimize safety problems, consistent with previous human studies (Grabowski et al, 2001, 2004a; Rush et al, 2009) and clinical practice (Herin et al, 2010). If SR-AMP were to be adopted in drug abuse treatment programs, similar safeguards would be needed to screen and monitor patients. Having noted this issue, it can also be concluded that for individuals who safely tolerated these SR-AMP doses, the medication was effective. Efficacy, as measured by reduced breakpoints, was observed in seven of eight completers (Figure 1). The maximum dose in this study $(60 \mathrm{mg} /$ day) exceeded the dose of $40 \mathrm{mg} /$ day in the laboratory study by Rush et al (2010), but matched the 
upper dose in two clinical trials (Grabowski et al, 2001, 2004a). These data also show that the lower SR-AMP dose (30 mg/day) was equal in efficacy to the higher dose $(60 \mathrm{mg} /$ day), suggesting that it may not be necessary to escalate the dose further in all individuals.

The primary limitation of this study is the relatively small sample size, leading to concerns about generalizability of the study findings. Nonetheless, we observed significant and mostly selective effects of SR-AMP on reduction of cocaineseeking (primary outcome) and cocaine-induced subjective effects (secondary outcome) without potentiation of cocaine-induced cardiovascular effects (safety outcome). Concerns about external validity are also mitigated by the fact that Rush et al $(2009,2010)$ observed SR-AMP attenuation of cocaine's reinforcing and subjective effects in cocaine-dependent individuals. Several animal studies also showed the ability of SR-AMP to reduce cocaine selfadministration using only a few rats or rhesus monkeys. Finally, two clinical trials with moderately sized samples showed the ability of SR-AMP to reduce cocaine use. On the other hand, some findings of this study were statistically marginal (eg, trend for SR-AMP to reduce baseline cocaine abstinence signs on the CSSA), probably owing to a lack of power. However, the study was not designed to detect effects on these secondary outcomes, rather the intent was to include a broad range of measures for hypothesis testing in future studies. Another limitation is that the routes of experimental drug administration used here (intramuscular HYD and intranasal COC) do not match the typical routes used naturalistically by these study participants (see Table 2). Specifically, intravenous/intranasal heroin and smoked cocaine (predominant among these subjects) may produce faster-onset pharmacokinetics with more profound pharmacodynamic results compared with our experimental routes. On the other hand, we consider these concerns to be mitigated in at least three ways. First, these pharmacodynamic effects should be qualitatively similar. Second, the designed staggering of HYD and COC administration (by $15 \mathrm{~min}$ ) succeeded in aligning peak responses to the two drugs (thus simulating speedball-like effects). Third, as noted above, these human laboratory results are concordant with both preclinical self-administration and clinical trial findings.

The scientific rationale for this study was based on two key ideas: (1) combining two agonist medications for treating cocaine/heroin abusers could be effective for reducing both types of illegal drug use, and (2) combining SR-AMP with a partial $\mu$-agonist (BUP) could be safer than with a full $\mu$-agonist (MTD). There may be several advantages to combining anti-cocaine medications such as SR-AMP with BUP, rather than MTD, aside from the important fact that BUP is another treatment option for the clinician and patient. First, BUP could be safer, better tolerated, or more preferred than MTD for some individuals. On the other hand, we recognize that some patients with more severe opioid physical dependence could benefit from MTD as a $\mu$-opioid full agonist medication in combination with SR-AMP. Alternatively, patients with less severe opioid addiction could initially be offered BUP in combination with SR-AMP and, if BUP does not prove effective, the patient could be switched directly to MTD in combination with SR-AMP; Herin et al (2010) recently discussed this type of graded agonist approach. Second, BUP is longer acting than MTD, which could facilitate lessthan-daily dosing; however, this is based on the non-trivial assumption that take-home doses of SR-AMP could be dispensed, which would have to be evaluated for safety and diversion concerns. Third, BUP can be prescribed by appropriately trained physicians in office-based settings, which could promote greater access to treatment and reduction in stigma to cocaine/heroin-dependent patients.

In conclusion, this study provides the first demonstration in the human laboratory setting that SR-AMP attenuates cocaine-seeking behavior, and that this effect is selective in cocaine/heroin-dependent individuals. These data are consistent with other preclinical and clinical data, suggesting that this is a robust effect. Given the large number of putative medications that have been evaluated and failed to reduce cocaine self-administration in the human laboratory setting and cocaine use in clinical trials, this is an important result. With proper attention paid to safety considerations, these novel findings suggest that a polypharmaceutical combination of higher-dose BUP and SR-AMP could be an effective approach for treating individuals who abuse cocaine and opioids.

\section{ACKNOWLEDGEMENTS}

NIH Grant R01 DA022243 from the National Institute on Drug Abuse and a research grant (Joe Young, Sr. funds) from the State of Michigan supported this research. This study was registered as NIH Clinical Trial NCT00429767 (http://clinicaltrials.gov/ct2/show/NCT00429767). We thank Dr Chris-Ellyn Johanson for consultation, Dr Carl Christensen for medical oversight, Ken Bates for recruitment, and Debra Kish, Joi Moore, and Lisa Sulkowski for data collection and management. We thank the staff of the Psychiatric and Addiction Research Center at Wayne State University for clinical data collection and safety monitoring.

\section{DISCLOSURE}

The authors declare no conflicts of interest in relationship to performing this study. Dr Greenwald has received compensation as a consultant to Reckitt-Benckiser Pharmaceuticals, the company that markets the buprenorphine products, Suboxone and Subutex. Both Dr Greenwald and Dr Steinmiller have received compensation from Titan Pharmaceuticals. Dr Lundahl has received compensation from Gateway Community Health (Michigan), and the National Football League.

\section{REFERENCES}

Anderson AL, Reid MS, Li S-H, Holmes T, Shemanski L, Slee A et al (2009). Modafinil for the treatment of cocaine dependence. Drug Alcohol Depend 104: 133-139.

Bach MV, Coutts RT, Baker GB (1999). Involvement of CYP2D6 in the in vitro metabolism of amphetamine, two $\mathrm{N}$-alkylamphetamines and their 4-methoxylated derivatives. Xenobiotica 29: 719-732.

Barrett AC, Miller JR, Dohrmann JM, Caine SB (2004). Effects of dopamine indirect agonists and selective D1-like and D2-like agonists and antagonists on cocaine self-administration and 
food maintained responding in rats. Neuropharmacology 47(Supp1): 256-273.

Beck AT, Steer RA, Ball R, Rainieri W (1996). Comparison of Beck Depression Inventories-IA and -II in psychiatric outpatients. J Pers Assess 67: 588-597.

Beswick T, Best D, Rees S, Coomber R, Gossup M, Strang J (2001). Multiple drug use: patterns and practices of heroin and crack use in a population of opiate addicts in treatment. Drug Alcohol Rev 20: 201-204.

Castells X, Casas M, Vidal X, Bosch R, Roncero C, Antoni J et al (2007). Efficacy of central nervous system stimulant treatment for cocaine dependence: a systematic review and meta-analysis of randomized controlled clinical trials. Addiction 102: 1871-1887.

Chiodo KA, Läck CM, Roberts DCS (2008). Cocaine self-administration reinforced on a progressive ratio schedule decreases with continuous $d$-amphetamine treatment in rats. Psychopharmacology 200: 465-473.

Chiodo KA, Roberts DCS (2009). Decreased reinforcing effects of cocaine following 2 weeks of continuous $d$-amphetamine treatment in rats. Psychopharmacology 206: 447-456.

Comer SD, Ashworth JB, Foltin RW, Johanson CE, Zacny JP, Walsh SL (2008). The role of human drug self-administration procedures in the development of medications. Drug Alcohol Depend 96: 1-15.

Comer SD, Walker EA, Collins ED (2005). Buprenorphine/ naloxone reduces the reinforcing and subjective effects of heroin in heroin-dependent volunteers. Psychopharmacology 181: 664-675.

Cornish JL, Lontos JM, Clemens KJ, McGregor IS (2005). Cocaine and heroin ('speedball') self-administration: the involvement of nucleus accumbens dopamine and $\mu$-opiate, but not $\delta$-opiate receptors. Psychopharmacology 180: 21-32.

Craddock SG, Rounds-Bryant JL, Flynn PM, Hubbard RL (1997). Characteristics and pretreatment behaviors of clients entering drug abuse treatment: 1969 to 1993. Am J Drug Alcohol Abuse 23: 43-59.

Cross JC, Johnson BD, Davis WR, Liberty HJ (2001). Supporting the habit: income generation activities of frequent crack users compared with frequent users of other hard drugs. Drug Alcohol Depend 64: 191-201.

Dackis CA, Kampman KM, Lynch KG, Pettinati HM, O'Brien CP (2005). A double-blind, placebo-controlled trial of modafinil for cocaine dependence. Neuropsychopharmacology 30: 205-211.

DeMaria Jr PA, Sterling R, Weinstein SP (2000). The effect of stimulant and sedative use on treatment outcome of patients admitted to methadone maintenance treatment. Am J Addict 9: $145-153$.

Downey KK, Helmus TC, Schuster CR (2000). Treatment of heroindependent polydrug abusers with contingency management and buprenorphine maintenance. Exp Clin Psychopharmacol 8: 176-184.

Duvauchelle CL, Sapoznik T, Kornetsky C (1998). The synergistic effects of combining cocaine and heroin ('speedball') using a progressive-ratio schedule of drug reinforcement. Pharmacol Biochem Behav 61: 297-302.

First MB, Spitzer RL, Gibbon M, Williams JBW (1996). Structured Clinical Interview for DSM-IV Axis Disorders-Patient Edition (SCID-I/P, Version 20). Biometrics Research Dept., NY State Psychiatric Institute: New York.

Foltin RW, Evans SM (1999). The effects of $d$-amphetamine on intake of food and a sweet fluid containing cocaine. Pharmacol Biochem Behav 62: 457-464.

Ginovart N, Farde L, Halldin C, Swahn CG (1999). Changes in striatal D2-receptor density following chronic treatment with amphetamine as assessed with PET in nonhuman primates. Synapse 31: 154-162.

Glowa JR, Wojnicki FHE, Matecka D, Rice KC, Rothman RB (1995). Effects of dopamine reuptake inhibitors on food- and cocaine-maintained responding: II. Comparisons with other drugs and repeated administrations. Exp Clin Psychopharmacol 3: 232-239.

Gorelick DA, Gardner EL, Xi ZX (2004). Agents in development for the management of cocaine abuse. Drugs 64: 1547-1573.

Grabowski J, Rhoades H, Schmitz J, Stotts A, Daruzska LA, Creson $\mathrm{D}$ et al (2001). Dextroamphetamine for cocaine dependence treatment: a double-blind randomized clinical trial. J Clin Psychopharmacol 21: 522-526.

Grabowski J, Rhoades H, Stotts A, Cowan K, Kopecky C, Dougherty A et al (2004a). Agonist-like or antagonist-like treatment for cocaine dependence with methadone for heroin dependence: two double-blind randomized clinical trials. Neuropsychopharmacology 29: 969-981.

Grabowski J, Shearer J, Merrill J, Negus SS (2004b). Agonist-like replacement pharmacotherapy for stimulant abuse and dependence. Addict Behav 29: 1439-1464.

Green CE, LeValley SE, Tyson CA (1986). Comparison of amphetamine metabolism using isolated hepatocytes from five species including human. J Pharmacol Exp Ther 237: 931-936.

Greenwald MK (2010). Effects of experimental unemployment, employment and punishment analogs on opioid seeking and consumption in heroin-dependent volunteers. Drug Alcohol Depend 111: 64-73.

Greenwald MK, Hursh SR (2006). Behavioral economic analysis of opioid consumption in heroin-dependent individuals: effects of unit price and pre-session drug supply. Drug Alcohol Depend 85: $35-48$.

Greenwald MK, Schuh KJ, Hopper JA, Schuster CR, Johanson CE (2002). Effects of buprenorphine sublingual tablet maintenance on opioid drug-seeking behavior by humans. Psychopharmacology 160: 344-352.

Greenwald MK, Steinmiller CL (2009). Behavioral economic analysis of opioid consumption in heroin-dependent individuals: effects of alternative reinforcer magnitude and postsession drug supply. Drug Alcohol Depend 104: 84-93.

Grella CE, Anglin MD, Wugalter SE (1995). Cocaine and crack use and HIV risk behaviors among high-risk methadone maintenance clients. Drug Alcohol Depend 37: 15-21.

Griffiths RR, Troisi JR, Silverman K, Mumford GK (1993). Multiple-choice procedure: an efficient approach for investigating drug reinforcement in humans. Behav Pharmacol 4: 3-13.

Haney M, Spealman R (2008). Controversies in translational research: drug self-administration. Psychopharmacology 199: 403-419.

Hart CL, Haney M, Vosburg SK, Rubin E, Foltin RW (2008). Smoked cocaine self-administration is decreased by modafinil. Neuropsychopharmacology 33: 761-768.

Herin DV, Rush CR, Grabowski J (2010). Agonist-like pharmacotherapy for stimulant dependence: preclinical, human laboratory, and clinical studies. Ann N Y Acad Sci 1187: 76-100.

Hudgins R, McCusker J, Stoddard A (1995). Cocaine use and risky injection and sexual behaviors. Drug Alcohol Depend 37: 7-14.

Jasinski DR (1977). Assessment of the abuse potentiality of morphine-like drugs (methods used in man). In: Martin WR (ed). Handbook of Experimental Pharmacology. Springer-Verlag: Heidelberg, West Germany. pp 197-258.

Johns MW (1991). A new method for measuring daytime sleepiness: the Epworth Sleepiness Scale. Sleep 14: 540-545.

Kampman KM, Volpicelli JR, McGinnis DE, Alterman AI, Weinrieb RM, D'Angelo L et al (1998). Reliability and validity of the Cocaine Selective Severity Assessment. Addict Behav 23: 449-461.

Kim JH, Perugini M, Austin JD, Vezina P (2001). Previous exposure to amphetamine enhances the subsequent locomotor response to a D1 dopamine receptor agonist when glutamate reuptake is inhibited. J Neurosci 21: RC133.

King VL, Kidorf MS, Stoller KB, Carter JA, Brooner RK (2001). Influence of antisocial personality subtypes on drug abuse treatment response. J Nerv Ment Dis 189: 593-601. 
Kleinknecht RA, Kleinknecht EE, Sawchuck CN, Lee T, Lohr JM (1999). Medical Fear Survey: psychometric properties. Behav Therapist 22: 109-119.

Kobayashi K, Yamamoto T, Chiba K, Tani M, Shimada N, Ishizaki T et al (1998). Human buprenorphine N-dealkylation is catalyzed by cytochrome P450 3A4. Drug Metab Dispos 26: 818-821.

Kreek MJ (2000). Methadone-related opioid agonist pharmacotherapy for heroin addiction. History, recent molecular and neurochemical research and future in mainstream medicine. Ann N Y Acad Sci 909: 186-216.

Leri F, Bruneau J, Stewart J (2004). Understanding polydrug use: review of heroin and cocaine co-use. Addiction 98: 7-22.

Li Y, Kauer JA (2004). Repeated exposure to amphetamine disrupts dopaminergic modulation of excitatory synaptic plasticity and neurotransmission in nucleus accumbens. Synapse 51: 1-10.

Lynch WJ, Heaser WA, Carroll ME (1998). Effects of amphetamine, butorphanol, and morphine pretreatment on the maintenance and reinstatement of cocaine-reinforced responding. Exp Clin Psychopharmacol 6: 255-263.

Magura S, Siddiqi Q, Freeman RC, Lipton DS (1991). Changes in cocaine use after entry to methadone treatment. J Addict Dis 10: $31-45$.

Mansbach RS, Balster RL (1993). Effects of mazindol on behavior maintained or occasioned by cocaine. Drug Alcohol Depend 31: 183-191.

Martin WR, Sloan JW, Sapiro JD, Jasinski DR (1971). Physiologic, subjective, and behavioral effects of amphetamine, methamphetamine, ephedrine, phenmetrazine, and methylphenidate in man. Clin Pharmacol Ther 12: 245-258.

Mello NK, Negus SS (1998). The effects of buprenorphine on selfadministration of cocaine and heroin 'speedball' combinations and heroin alone by rhesus monkeys. J Pharmacol Exp Ther 295: 444-456.

Mello NK, Negus SS (2007). Effects of $d$-amphetamine and buprenorphine combinations on speedball (cocaine+heroin) self-administration by rhesus monkeys. Neuropsychopharmacology 32: 1985-1994.

Mello NK, Negus SS, Lukas SE, Mendelson JH, Sholar JW, Drieze J (1995). A primate model of polydrug abuse: cocaine and heroin combinations. Pharmacol Exp Ther 274: 1325-1337.

Montoya ID, Gorelick DA, Preston KL, Schroeder JR, Umbricht A, Cheskin LJ et al (2004). Randomized trial of buprenorphine for treatment of concurrent opiate and cocaine dependence. Clin Pharmacol Ther 75: 34-48.

Moody DE, Slawson MH, Strain EC, Laycock JD, Spanbauer AC, Foltz RL (2002). A liquid chromatographic-electrospray ionization-tandem mass spectrometric method for determination of buprenorphine, its metabolite, norbuprenorphine, and a coformulant, naloxone, that is suitable for in vivo and in vitro metabolism studies. Anal Biochem 306: 31-39.

Negus SS (2003). Rapid assessment of choice between cocaine and food in rhesus monkeys: effects of environmental manipulations and treatment with $d$-amphetamine and flupenthixol. Neuropsychopharmacology 28: 919-931.

Negus SS (2005). Interactions between the reinforcing effects of cocaine and heroin in a drug- $v s$-food choice procedure in rhesus monkeys: a dose-addition analysis. Psychopharmacology 180: 115-124.

Negus SS, Mello NK (2003a). Effects of chronic $d$-amphetamine treatment on cocaine- and food-maintained responding under a second-order schedule in rhesus monkeys. Drug Alcohol Depend 70: $39-52$.

Negus SS, Mello NK (2003b). Effects of chronic $d$-amphetamine treatment on cocaine- and food-maintained responding under a progressive-ratio schedule in rhesus monkeys. Psychopharmacology 167: 324-332.

Office of National Drug Control Policy (ONDCP) (2003). Economic Costs of Drug Aabuse in the United States: 1992-2002.
Peltier RL, Li DH, Lytle D, Taylor CM, Emmett-Oglesby MW (1996). Chronic $d$-amphetamine or methamphetamine produces cross-tolerance to the discriminative and reinforcing stimulus effects of cocaine. J Pharmacol Exp Ther 277: 212-218.

Perez DLC, Trujols J, Ribalta E, Casas M (1997). Cocaine use immediately prior to entry in an inpatient heroin detoxification unit as a predictor of discharges against medical advice. $A m \mathrm{~J}$ Drug Alcohol Abuse 23: 267-269.

Preston KL, Silverman K, Higgins ST, Brooner RK, Montoya I, Schuster CR et al (1998). Cocaine use early in treatment predicts outcome in a behavioral treatment program. J Consult Clin Psychol 66: 691-696.

Rothman RB, Blough BE, Baumann MH (2002). Appetite suppressants as agonist substitution therapies for stimulant dependence. Ann N Y Acad Sci 965: 109-126.

Rowlett JK, Rodefer JS, Spealman RD (2005). Self-administration of cocaine-opioid combinations by rhesus monkeys: evaluation of the role of mu receptor efficacy using labor supply analysis. J Pharmacol Exp Ther 312: 1289-1297.

Rowlett JK, Wilcox KM, Woolverton WL (1998). Self-administration of cocaine-heroin combinations by rhesus monkeys: antagonism by naltrexone. J Pharmacol Exp Ther 286: 61-69.

Rowlett JK, Woolverton WL (1997). Self-administration of cocaine and heroin combinations by rhesus monkeys responding under a progressive-ratio schedule. Psychopharmacology 133: 363-371.

Rush CR, Baker RW, Wright K (1999). Acute physiological and behavioral effects of oral cocaine in humans: a dose-response analysis. Drug Alcohol Depend 55: 1-12.

Rush CR, Stoops WW, Hays LR (2009). Cocaine effects during $d$-amphetamine maintenance: a human laboratory analysis of safety, tolerability and efficacy. Drug Alcohol Depend 99: 261-271.

Rush CR, Stoops WW, Sevak RJ, Hays LR (2010). Cocaine choice in humans during d-amphetamine maintenance. J Clin Psychopharmacol 30: 152-159.

Schottenfeld RS, Pakes J, Ziedonis D, Kosten TR (1993). Buprenorphine: dose-related effects on cocaine and opioid use in cocaine-abusing opioid-dependent humans. Biol Psychiatry 34: 66-74.

Schuster CR, Greenwald MK, Johanson CE, Heishman SJ (1995). Measurement of drug craving during naloxone-precipitated withdrawal in methadone maintained volunteers. Exp Clin Psychopharmacol 3: 424-431.

Schütz CG, Vlahov D, Anthony JC, Graham NMH (1994). Comparison of self-reported injection frequencies for past 30 days and 6 months among intravenous drug users. J Clin Epidemiol 47: 191-195.

Shearer J, Gowing LR (2004). Pharmacotherapies for problematic psychostimulant use: a review of current research. Drug Alcohol Rev 23: 203-211.

Sofuoglu M, Gonzalez G, Poling J, Kosten TR (2003). Prediction of treatment outcome by baseline urine cocaine results and selfreported cocaine use for cocaine and opioid dependence. $A m \mathrm{~J}$ Drug Alcohol Abuse 29: 713-727.

Strug DL, Hunt DE, Goldsmith DS, Lipton DS, Spunt B (1985). Patterns of cocaine use among methadone clients. Int J Addict 20: $1163-1175$.

Sussner BD, Smelson DA, Rodrigues S, Kline A, Losonczy M, Ziedonis D (2006). The validity and reliability of a brief measure of cocaine craving. Drug Alcohol Depend 83: 233-237.

Tiffany ST, Singleton E, Haertzen CA, Henningfield JE (1993). The development of a cocaine craving questionnaire. Drug Alcohol Depend 34: 19-28.

Tomkins DM, Otten SV, Joharchi N, Berns T, Wu D, Corrigal WA et al (1997). Effect of CYP2D1 inhibition on the behavioural effects of $d$-amphetamine. Behav Pharmacol 8: 223-235.

Torrens M, San L, Peri JM, Olle JM (1991). Cocaine abuse among heroin addicts in Spain. Drug Alcohol Depend 27: 29-34. 
Tzilos GK, Rhodes GL, Ledgerwood DM, Greenwald MK (2009). Predicting cocaine group treatment outcome in cocaine-abusing methadone-maintained patients. Exp Clin Psychopharmacol 17: $320-325$.

Umehara K, Shimokawa Y, Miyamoto G (2002). Inhibition of human drug metabolizing cytochrome $\mathrm{P} 450$ by buprenorphine. Biol Pharm Bull 25: 682-685.

Winger G, Galuska CM, Hursh SR, Woods JH (2006). Relative reinforcing effects of cocaine, remifentanil, and their combination in rhesus monkeys. J Pharmacol Exp Ther 318: 223-229.
Woolverton WL, Wang Z, Vasterling T, Tallarida R (2008). Self-administration of cocaine-remifentanil mixtures by monkeys: an isobolographic analysis. Psychopharmacology 198: 387-394.

Zachary RA (1991). Shipley Institute of Living Scale: Revised Manual. Western Psychological Services: Los Angeles, CA.

Zhang W, Ramamoorthy Y, Tyndale RF, Sellers EM (2003). Interaction of buprenorphine and its metabolite norbuprenorphine with cytochromes p450 in vitro. Drug Metab Dispos 31: 768-772. 